\title{
Psychological Distress in Caregivers for People With Dementia: A Population-Based Analysis of A National Cross-Sectional Study
}

Norio Sugawara ( $\square$ nsuga3@dokkyomed.ac.jp )

Dokkyo Medical University School of Medicine

Norio Yasui-Furukori

Dokkyo Medical University School of Medicine

Kazushi Maruo

University of Tsukuba

Kazutaka Shimoda

Dokkyo Medical University School of Medicine

Tomiki Sumiyoshi

National Center of Neurology and Psychiatry

Research Article

Keywords: caregiver burden, psychological distress, nursing care, dementia

Posted Date: January 8th, 2021

DOl: https://doi.org/10.21203/rs.3.rs-140853/v1

License: (c) (i) This work is licensed under a Creative Commons Attribution 4.0 International License. Read Full License

Version of Record: A version of this preprint was published at Journal of Alzheimer's Disease on November 27th, 2021. See the published version at https://doi.org/10.3233/JAD-210680. 


\section{Abstract}

Background: Informal caregivers (CGs), also called family caregivers, play an important role in supporting the well-being of and providing care to older people with dementia. However, taking care of patients with dementia is often stressful and exhausting. To facilitate the sustainable provision of care to people with dementia at home, it is crucial to reduce the burden placed on CGs. The aim of this study was to evaluate the psychological distress experienced by CGs for care recipients with dementia (CRDs) and identify the sociodemographic factors affecting that distress.

Methods: We utilized the 2013 Comprehensive Survey of the Living Conditions for CRDs and CGs. Linked data from 643 pairs of CRDs and CGs were extracted. The psychological distress experienced by CGs was measured by Kessler's Psychological Distress scale (K6) with a cutoff point of 13 . Factors predictive of psychological distress were evaluated using multivariable logistic regression analysis with the forward selection method.

Results: Overall, the mean age of the CGs was $63.5 \pm 11.6$ years, and $5.3 \%(34 / 643)$ experienced serious psychological distress. Male sex of CRDs, knowing how to access consulting services, spending almost all day for nursing care, and having subjective symptoms within a few days were associated with having serious psychological distress, while older age, participating in shopping as part of the nursing, and having their own house were related to freedom from serious psychological distress.

Conclusions: Clinicians should be aware of the risk factors for psychological distress in CGs and consider providing support to reduce the burden imposed by modifiable factors. Further studies are warranted to examine whether such efforts would improve the mental health of CGs for CRDs.

\section{Background}

Informal caregivers (CGs), who are individuals caring for their relatives, usually without payment, play an important role in supporting the well-being and health of older people with disabilities [1]. With the rapid increase in the number of elderly individuals in Japan, dementia has become a leading cause of the need for long-term care (LTC) [2]. Caring for care recipients with dementia (CRDs) has often been regarded as stressful and exhausting [3]. In fact, the CGs burden may adversely affect their emotional, social, financial, physical, and spiritual functioning [4], making it a major concern in an aging society.

In Japan, the public LTC insurance system was started in 2000 to relieve the burden on CGs [5]. In 2012, the Ministry of Health, Labor, and Welfare (MHLW) launched the Orange Plan for the early detection and care of elderly people with dementia and the provision of support to CGs [6]. At present, most CRDs are taken care of by family members in Japan, and more than $70 \%$ of LTC is provided at home [7]. Although most elderly Japanese people want to continue to live in their house and community [8], a heavy burden on the CGs has been found to predict the admission of care recipients to a nursing care institution $[9,10]$. Therefore, it is crucial to reduce the burden on CGs to facilitate the sustainable provision of care to CRDs at home [11]. 
To date, several interventions targeting psychological distress in CGs have been tested. However, a recent meta-analysis investigating the usefulness of educational interventions found only a small effect on the psychological burden experienced by CGs [12]. Given the increasing numbers of CRDs, it is necessary to clarify the social factors that predict psychological distress in CGs.

The purpose of this study was to evaluate psychological distress in CGs of CRDs and identify the associated sociodemographic factors. Accordingly, we conducted an analysis of cross-sectional data from the 2013 Comprehensive Survey of Living Conditions (CSLC). These data were collected nationwide by the MHLW and are representative of the Japanese population [13].

\section{Methods}

\section{Participants}

The 2013 CSLC targeted 295,367 households based on 5,530 randomly selected enumeration districts (EDs) of the 2010 Population Census, and 234,383 households (79.4\%) completed the 'household questionnaire' and the 'health questionnaire' in June-July 2013 [13]. All household members, except for those who did not live at home during the survey period, responded to the questionnaires. The 'LTC questionnaire' was distributed $(n=7,270)$ to 2,500 randomly selected EDs from the original 5,530 EDs, and 6,342 questionnaires were collected from households with a member who was officially certified as needing LTC at the time of the survey.

The flowchart showing the process of extracting the data for our quantitative analysis is presented in Figure 1. Among the 6,342 responses to the LTC questionnaire, we identified the nursing care recipients whose main reason for receiving care was dementia $(n=1,042)$. Based on the household questionnaire, the main CGs for the abovementioned household members were identified, and 683 CRDs with family CGs were extracted. We then excluded CGs who lacked data on age, sex, and psychological distress. The remaining 643 dyads of CRDs and their main CGs were included in the analysis.

This study was approved by the ethics review committee of the National Center of Neurology and Psychiatry (approval number: A2017-001) and it conformed to the provisions of the Declaration of Helsinki, and Japanese Ethical Guidelines for Medical and Health Research Involving Human Subjects. We obtained permission to use certain data from the 2013 CSLC for purposes other than those originally intended by the MHLW according to the Statistics Act, Article 33. Because we did not use any personally identifiable information, the requirement for written informed consent was waived by the Ethics Committee and the Statistics Act since the study involved record review only.

\section{Measures}

Kessler's Psychological Distress scale (K6) was used to measure psychological distress in the CSLC. The K6 scale was developed as a brief screening tool for nonspecific psychological distress in adults and consists of 6 questions asking about psychological symptoms in the previous month $[15,16]$. In line with 
the recommended K6 cutoff point, we defined serious psychological distress according to a K6 score $\geq 13$ [17].

As independent variables of the CRDs, we included data on levels of LTC needs as well as demographics (age, and sex). Regarding the main CGs, we extracted data from the 2013 CSLC on the following variables: age, sex, relationship with the CRD, marital status, educational attainment, having someone to consult with, knowing how to access consulting services, time spent on nursing care (almost all day, other), participation in 16 nursing activities, the presence or absence of subjective symptoms within the last few days, paid work, and regular visit of hospitals. With respect to household factors, we used data concerning the number of family members at home, total household monthly expenditures, the presence or absence of other family members in need of nursing care, and house ownership.

\section{Statistical Analysis}

Analyses were conducted using SAS version 9.4 (SAS Institute Inc., Cary, NC, USA). To describe the sociodemographic characteristics of participants stratified by the presence or absence of serious psychological distress, we conducted unpaired Student's t-tests and chi-square tests for continuous variables and categorical variables, respectively. Continuous variables are presented as the means \pm SDs.

To examine the association between CGs' psychological distress $(K 6 \geq 13)$ and factors related to CRDs, CGs, and households, we conducted multivariable logistic regression analysis using a forward selection method based on the score test (selection criteria: $\mathrm{p}<0.05$ ). In that analysis, the dependent variable was CGs' psychological distress, and the independent variables were factors related to the CRDs (age, sex, and level of LTC required), CGs (age, sex, relationship with CRD, marital status, educational attainment, having someone to consult with, knowing how to access consulting services, time spent on nursing care, participation in 16 nursing activities, having subjective symptoms within a few days, and regularly visiting hospitals), and household (number of family members at home, house ownership, total household monthly expenditures, and other family members in need of nursing care). The $\mathrm{C}$ statistic and Hosmer-Lemeshow test were employed to evaluate the goodness-of-fit of the estimated logistic model. We considered a value of $P<0.05$ to be significant.

\section{Results}

Overall, the mean age of the CGs was $63.5 \pm 11.6$ years, and the proportion of CGs with serious psychological distress was $5.3 \%$ (34/643). Analysis of the influence of sociodemographic data on psychological distress (Table 1) showed that CGs with serious distress were significantly younger, having male CRDs, having someone to consult with, to know how to access consulting services, spending almost all day for nursing care, and to have had subjective symptoms within a few days. In addition, CGs who participated more in cleaning up and shopping when providing nursing care and had their own house were less likely to have serious psychological distress. 
To evaluate the predictors of psychological distress in CGs, we performed a multivariable logistic regression analysis with the forward selection method (Table 2). In that analysis, having male CRDs, knowing how to access consulting services, spending almost all day for nursing care, and having subjective symptoms within a few days were associated with having serious psychological distress. Being older, participating in shopping as a form of nursing care, and having their own house were related to the absence of serious psychological distress. The $\mathrm{C}$ statistic and Hosmer-Lemeshow test yielded a $\mathrm{C}$ of 0.840 and $p$ of 0.728 , respectively.

\section{Discussion}

This study evaluated potential associations between psychological distress in CGs and caring for a CRD at home in Japan. Twenty-four percent (154/643) of CGs were found to spend most of their time on nursing CRDs, and $44.5 \%$ (286/643) of the CGs had their own health problems. Approximately $5 \%$ (34/643) of CGs reported that they experienced serious psychological distress. Multivariable logistic regression analysis revealed the association between serious psychological distress and male sex of the CRDs, younger age of the CGs, knowing how to access consulting services, spending almost all day for nursing care, not participating in shopping as part of nursing, having subjective symptoms within a few days, and not owning a house.

In our study, CGs who nursed male CRDs had greater psychological distress than those who nursed female CRDs, which is not consistent with some previous studies [18-21]. A possible explanation for this discrepancy is the difference in kinship between CGs and CRDs. In Japan, the majority of (informal) CGs at home are spouses, offspring, and spouses of offspring of CRDs [8]. A recent study showed that female CGs who were spouses of the offspring of male CRDs experienced greater psychological distress than CGs with other relationships to the CRDs [22]. Another explanation is that sex-based differences in the behavioral and psychological symptoms of dementia (BPSD) could affect psychological distress in CGs. Specifically, men with dementia have been reported to exhibit aggressive behaviors and diurnal rhythm disturbance more frequently than their female counterparts $[23,24]$. These considerations are in line with the suggestion that the sex of CRDs would affect physical and financial distress among their CGs [18].

Social support for the CGs of CRDs has been regarded as an important intervention because support programs could improve the psychological status of CGs as well as their ability to take care of the CRDs [25-27]. However, data from our study indicate that participants who knew how to access consulting services still experienced serious psychological distress. We cannot completely explain these conflicting results. It may be that a number of CGs might be reluctant to use social support services or receive adequate support, in spite of their knowledge of helpful resources [28].

Our results showed that spending almost all day on nursing care was associated with serious psychological distress in CGs. Nursing CRDs requires more time than nursing elderly people without dementia [29], and spending substantial time caring for CRDs has been associated with the heaviness of the burden imposed on CGs [29, 30]. Specifically, caring for CRDs at home involves a variety of tasks, 
such as changing clothes, washing, toileting, assisting with eating, or helping with medication, producing subjective burden experienced by CGs [31]. Although we did not identify specific tasks that could elevate their distress, the findings in our study might be explained by a lack of data concerning the time spent on each task.

Spending almost all day engaged in nursing, which indicates an absence of relief, could accelerate the social isolation of CGs [32,33]. A recent study in Japan reported that participation of CGs in social activities may protect their mental health [34]. In that context, shopping as a form of nursing care may serve as a form of the social engagement for CGs. In fact, our results indicate that participating in shopping was related to freedom from serious psychological distress.

Our results demonstrated that subjective symptoms of CGs were associated with their psychological distress. CGs have been shown to be at a higher risk of mental and physical health problems, even after adjusting for confounders $[35,36]$. Specifically, subjective symptoms of CGs have been shown as risk factor of harmful behavior for care recipients [37]. As the burden on CGs is associated with adverse health outcomes in care recipients [10,38], it is important for clinicians to consider ways to reduce the burden on CGs imposed by the need to provide nursing care to CRDs.

Previous studies have reported the relationship between house ownership and nursing care at home [3941]. For example, the lack of house ownership has been shown to accelerate the institutionalization of CRDs [39, 40]. In addition, a recent study found protective effects of house ownership against psychological distress in CGs, consistent with our results [41]. In Japan, more than half of the households own their homes [42]. CGs who own their houses may be able to more easily prepare safer and more feasible environments in which to provide care. On the other hand, we did not find an association between monthly expenditures and psychological distress. Therefore, house ownership may provide a better indicator of household wealth than expenditures [43].

The current study has several limitations. First, its cross-sectional nature does not allow for causal conclusions to be drawn with regard to care-related stress factors and serious psychological distress in the CGs studied here. Further studies with longitudinal designs are needed to investigate these associations. Second, BPSDs, such as hallucinations, delusions, agitation, disinhibition, apathy, anxiety, and changes in sleep or appetite, were not included in the CSLC dataset, although they could have impacted adversely on the mental health of CGs [44]. Finally, the CSLC lacks data on some characteristics of CRDs, such as cognitive function, although it included the levels of LTC based on the Japanese insurance scheme. In the Japanese scheme, the levels of LTC are decided not by cognitive function but by the intensity of cares needed.

\section{Conclusion}

Spending a substantial amount of time nursing CRDs may be associated with the psychological burden imposed on CGs. To facilitate the sustainable provision of care to people with dementia at home, effective support programs are needed for CGs who are engaged in providing care almost all day long 
and/or have their own health problems. Further studies are warranted to develop interventions targeting the psychological distress experienced by CGs.

\section{Abbreviations}

CGs, Caregivers, K6, Kessler's Psychological Distress scale, CRD, Care Recipients with Dementia, LTC, Long-Term Care, MHLW, Ministry of Health, Labor, and Welfare, CSLC, Comprehensive Survey of Living Conditions, BPSD, Behavioral and Psychological Symptoms of Dementia.

\section{Declarations}

\section{Ethics approval and consent to participate}

This study was approved by the ethics review committee of the National Center of Neurology and Psychiatry (approval number: A2017-001). We obtained permission to use certain data from the 2013 CSLC for purposes other than those originally intended by the MHLW according to the Statistics Act, Article 33. Because we did not use any personally identifiable information, consent to participate was not required.

\section{Consent for publication}

Not applicable.

\section{Availability of data and material}

The datasets used in this study are available from the MHLW (contact via https://www.mhlw.go.jp/toukei/sonota/chousahyo.html) for researchers who obtain approval to use the anonymous data in accordance with Statistics Act, Article 33.

\section{Competing interests}

The authors report no conflicts of interest related to this work.

\section{Funding}

The authors received no specific funding for this work.

\section{Author contributions}

N.S., N.Y.F., K.M., K.S., and T.S. contributed to study design, interpretation, and writing/review of this publication, including approval of the final manuscript. K.M. performed the statistical analyses. N.S., N.Y.F., K.M., K.S., and T.S. read and approved the final manuscript.

\section{Acknowledgments}


We would like to thank the members of the Translational Medical Center, National Center of Neurology and Psychiatry, for their kind support.

\section{References}

1. Adelman RD, Tmanova LL, Delgado D, Dion S, Lachs MS. Caregiver burden: a clinical review. JAMA. 2014;311(10):1052-60. doi: 10.1001/jama.2014.304.

2. Cabinet Office, Government of Japan. Annual Report on the Aging Society 2020. (in Japanese). https://www8.cao.go.jp/kourei/whitepaper/index-w.html Accessed 27 October 2020.

3. von Kutzleben M, Schmid W, Halek M, Holle B, Bartholomeyczik S. Community-dwelling persons with dementia: what do they need? What do they demand? What do they do? A systematic review on the subjective experiences of persons with dementia. Aging Ment Health. 2012;16(3):378-90. doi: 10.1080/13607863.2011.614594.

4. Zarit SH, Todd PA, Zarit JM. Subjective burden of husbands and wives as caregivers: a longitudinal study. Gerontologist. 1986;26(3):260-6. doi: 10.1093/geront/26.3.260.

5. Tamiya N, Noguchi $H$, Nishi A, Reich MR, Ikegami N, Hashimoto $H$, et al. Population ageing and wellbeing: lessons from Japan's long-term care insurance policy. Lancet. 2011;378(9797):1183-92. doi: 10.1016/S0140-6736(11)61176-8.

6. Nakanishi M, Nakashima T. Features of the Japanese national dementia strategy in comparison with international dementia policies: How should a national dementia policy interact with the public health- and social-care systems? Alzheimers Dement. 2014;10(4):468-476.e3. doi:

10.1016/j.jalz.2013.06.005.

7. Ministry of Health, Labour and Welfare. Statistics of Long-term Care Benefit Expenditures. (in Japanese). http://www.mhlw.go.jp/toukei/list/45-1b.html. Accessed 27 October 2020.

8. Cabinet Office, Government of Japan. Annual Report on the Aging Society 2018. (in Japanese). https://www8.cao.go.jp/kourei/whitepaper/w-2018/html/zenbun/s1_2_2.html Accessed 27 October 2020.

9. Kuzuya M, Hasegawa J, Hirakawa Y, Enoki H, Izawa S, Hirose T, et al. Impact of informal care levels on discontinuation of living at home in community-dwelling dependent elderly using various community-based services. Arch Gerontol Geriatr. 2011;52(2):127-32. doi:

10.1016/j.archger.2010.02.016.

10. Kuzuya M, Enoki H, Hasegawa J, Izawa S, Hirakawa $\mathrm{Y}$, Shimokata $\mathrm{H}$, et al. Impact of caregiver burden on adverse health outcomes in community-dwelling dependent older care recipients. Am J Geriatr Psychiatry. 2011;19(4):382-91. doi: 10.1097/JGP.0b013e3181e9b98d.

11. Cuijpers P. Depressive disorders in caregivers of dementia patients: a systematic review. Aging Ment Health. 2005;9(4):325-30. doi: 10.1080/13607860500090078.

12. Jensen M, Agbata IN, Canavan M, McCarthy G. Effectiveness of educational interventions for informal caregivers of individuals with dementia residing in the community: systematic review and 
meta-analysis of randomised controlled trials. Int J Geriatr Psychiatry. 2015;30(2):130-43. doi: 10.1002/gps.4208.

13. Ministry of Health, Labour and Welfare. 2013 Comprehensive Survey of Living Conditions. (in Japanese). https://www.mhlw.go.jp/toukei/saikin/hw/k-tyosa/k-tyosa13/index.html Accessed 14 Nopvember 2020.

14. Statistics Bureau, Ministry of Internal Affairs and Communications, Government of Japan. Census 2015. https://www.stat.go.jp/english/data/kokusei/2015/poj/mokuji.html Accessed 1 December 2019.

15. Kessler RC, Andrews G, Colpe LJ, Hiripi E, Mroczek DK, Normand SL ,et al. Short screening scales to monitor population prevalences and trends in non-specific psychological distress. Psychol Med. 2002;32(6):959-76. doi: 10.1017/s0033291702006074

16. Furukawa TA, Kawakami N, Saitoh M, Ono Y, Nakane Y, Nakamura Y, et al. The performance of the Japanese version of the K6 and K10 in the World Mental Health Survey Japan. Int J Methods Psychiatr Res. 2008;17(3):152-8. doi: 10.1002/mpr.257

17. Sakurai K, Nishi A, Kondo K, Yanagida K, Kawakami N. Screening performance of K6/K10 and other screening instruments for mood and anxiety disorders in Japan. Psychiatry Clin Neurosci. 2011;65(5):434-441. doi: 10.1111/j.1440-1819.2011.02236.x

18. Nagatomo I, Akasaki Y, Uchida M, Tominaga M, Hashiguchi W, Takigawa M. Gender of demented patients and specific family relationship of caregiver to patients influence mental fatigue and burdens on relatives as caregivers. Int J Geriatr Psychiatry. 1999;14(8):618-25. doi: 10.1002/(sici)1099-1166(199908)14:8<618::aid-gps989>3.0.co;2-b.

19. Oura A, Washio M, Arai Y, Ide S, Yamasaki R, Wada J, et al. Depression among caregivers of the frail elderly in Japan before and after the introduction of the Public Long-Term Care Insurance System. $Z$ Gerontol Geriatr. 2007;40(2):112-8. doi: 10.1007/s00391-007-0412-z.

20. Hasegawa N, Hashimoto M, Koyama A, Ishikawa T, Yatabe $Y$, Honda K, et al. Patient-related factors associated with depressive state in caregivers of patients with dementia at home. J Am Med Dir Assoc. 2014;15(5):371.e15-8. doi: 10.1016/j.jamda.2014.02.007.

21. Shikimoto R, Sado M, Ninomiya A, Yoshimura K, lkeda B, Baba T, et al. Predictive factors associated with psychological distress of caregivers of people with dementia in Japan: a cross-sectional study. Int Psychogeriatr. 2018;30(8):1089-1098. doi: 10.1017/S1041610217002289.

22. Iwata N, Horiguchi K. Differences in caregivers' psychological distress and associated factors by care recipients' gender and kinship. Aging Ment Health. 2016;20(12):1277-1285. doi:

10.1080/13607863.2015.1074161.

23. Lövheim H, Sandman PO, Karlsson S, Gustafson Y. Sex differences in the prevalence of behavioral and psychological symptoms of dementia. Int Psychogeriatr. 2009;21(3):469-75. doi:

$10.1017 /$ S1041610209008497.

24. Kitamura T, Kitamura M, Hino S, Tanaka N, Kurata K. Gender differences in clinical manifestations and outcomes among hospitalized patients with behavioral and psychological symptoms of 
dementia. J Clin Psychiatry. 2012;73(12):1548-54. doi: 10.4088/JCP.11m07614.

25. Han JW, Jeong H, Park JY, Kim TH, Lee DY, Lee DW, et al. Effects of social supports on burden in caregivers of people with dementia. Int Psychogeriatr. 2014;26(10):1639-48. doi:

10.1017/S1041610214001331.

26. Li Y, Hu L, Mao X, Shen Y, Xue H, Hou P, et al. Health literacy, social support, and care ability for caregivers of dementia patients: Structural equation modeling. Geriatr Nurs. 2020;41(5):600-607. doi: 10.1016/j.gerinurse.2020.03.014.

27. Dam AE, de Vugt ME, Klinkenberg IP, Verhey FR, van Boxtel MP. A systematic review of social support interventions for caregivers of people with dementia: Are they doing what they promise? Maturitas. 2016;85:117-30. doi: 10.1016/j.maturitas.2015.12.008.

28. Dam AEH, Boots LMM, van Boxtel MPJ, Verhey FRJ, de Vugt ME. A mismatch between supply and demand of social support in dementia care: a qualitative study on the perspectives of spousal caregivers and their social network members. Int Psychogeriatr. 2018;30(6):881-892. doi: 10.1017/S1041610217000898.

29. Vaingankar JA, Chong SA, Abdin E, Picco L, Jeyagurunathan A, Zhang Y, et al. Care participation and burden among informal caregivers of older adults with care needs and associations with dementia. Int Psychogeriatr. 2016;28(2):221-31. doi: 10.1017/S104161021500160X.

30. Carvalho EB, Neri AL. Time use by family caregivers of elderly with dementia: an integrative review. Rev Bras Enferm. 2018;71 Suppl 2:893-904. doi: 10.1590/0034-7167-2017-0268.

31. Oldenkamp M, Hagedoorn M, Slaets J, Stolk R, Wittek R, Smidt N. Subjective burden among spousal and adult-child informal caregivers of older adults: results from a longitudinal cohort study. BMC Geriatr. 2016;16(1):208. doi: 10.1186/s12877-016-0387-y.

32. Kovaleva M, Spangler S, Clevenger C, Hepburn K. Chronic Stress, Social Isolation, and Perceived Loneliness in Dementia Caregivers. J Psychosoc Nurs Ment Health Serv. 2018;56(10):36-43. doi: 10.3928/02793695-20180329-04.

33. Kitamura T, Tanimoto C, Oe S, Kitamura M, Hino S. Familial caregivers' experiences with home-visit nursing for persons with dementia who live alone. Psychogeriatrics. 2019;19(1):3-9. doi: $10.1111 /$ psyg. 12352 .

34. Noguchi T, Nakagawa-Senda H, Tamai Y, Nishiyama T, Watanabe M, Kamiya M, et al. The Association between Family Caregiver Burden and Subjective Well-Being and the Moderating Effect of Social Participation among Japanese Adults: A Cross-Sectional Study. Healthcare (Basel). 2020;8(2):87. doi: 10.3390/healthcare8020087.

35. Schulz R, Beach SR. Caregiving as a risk factor for mortality: the Caregiver Health Effects Study. JAMA. 1999;282(23):2215-9. doi: 10.1001/jama.282.23.2215.

36. Goren A, Montgomery W, Kahle-Wrobleski K, Nakamura T, Ueda K. Impact of caring for persons with Alzheimer's disease or dementia on caregivers' health outcomes: findings from a community based survey in Japan. BMC Geriatr. 2016;16:122. doi: 10.1186/s12877-016-0298-y. 
37. Beach SR, Schulz R, Williamson GM, Miller LS, Weiner MF, Lance CE. Risk factors for potentially harmful informal caregiver behavior. J Am Geriatr Soc. 2005 ;53(2):255-61 . doi: 10.1111/j.15325415.2005.53111.x.

38. Stall NM, Kim SJ, Hardacre KA, Shah PS, Straus SE, Bronskill SE, et al. Association of Informal Caregiver Distress with Health Outcomes of Community-Dwelling Dementia Care Recipients: A Systematic Review. J Am Geriatr Soc. 2019;67(3):609-617. doi: 10.1111/jgs.15690.

39. Kuroda K, Zhao L, Okamoto E, Takatorige T, Shinsho F, Tatara K. A comparative study of the characteristics and social backgrounds of frail and elderly persons at home, long-stay elderly hospital patients, and residents of welfare homes for the frail elderly. Nihon Koshu Eisei Zasshi. 1992;39(4):215-22. (in Japanese)

40. Kishida K, Tanizaki S. Determinants of urgency of nursing home placement. Nihon Koshu Eisei Zasshi. 2008;55(5):295-305. (in Japanese)

41. Tough H, Brinkhof MWG, Siegrist J, Fekete C, SwiSCI Study Group. Social inequalities in the burden of care: a dyadic analysis in the caregiving partners of persons with a physical disability. Int $J$ Equity Health. 2019;19(1):3. doi: 10.1186/s12939-019-1112-1

42. Statistics Bureau, Ministry of Internal Affairs and Communications, Government of Japan. Housing and Land Survey. https://www.stat.go.jp/data/jyutaku/index.html Accessed 31 December 2019.

43. Robert S, House JS. SES differentials in health by age and alternative indicators of SES. J Aging Health. 1996;8(3):359-88. doi: 10.1177/089826439600800304

44. Truzzi A, Valente L, Engelhardt E, Laks J. The association between caregiver distress and individual neuropsychiatric symptoms of dementia. Dement Neuropsychol. 2013;7(3):286-291. doi: 10.1590/S1980-57642013DN70300009.

\section{Tables}

Table 1. Sociodemographic characteristics stratified by serious psychological distress. 
K6 score

$<13$
K6 score

$\geq 13$ $\mathrm{p}$

value

Nursing care recipients

Age

$85.6 \pm \quad(n=609)$

5.8

Sex (being male)

$29.1 \%$

(177/609)

$55.9 \%$

$(19 / 34) \quad 0.001$

Levels of LTC required

Support Level 1 or 2 , or LTC Level 1

$37.1 \%$

(224/607) 29.4\%

$(10 / 34) \quad 0.230$

LTC Level 2 or 3

$45.0 \%$

$(272 / 607)$

$41.2 \%$

(14/34)

LTC Level 4 or 5

$17.9 \%$

(108/607) 29.4\%

$(10 / 34)$

Family caregivers

Age

$63.6 \pm \quad(n=609)$

11.5

$28.9 \%$

(176/609) 26.5\%

(9/34)

0.761

Sex (being male)

Relationship with nursing care recipients

Spouse

Offspring

Offspring spouse

Others
$25.0 \%$

$40.4 \%$

$30.2 \%$

$4.4 \%$

$79.6 \%$

$(485 / 609)$

$67.6 \%$

$(61 / 609) \quad 20.6 \%$

$(63 / 609)$

$11.8 \%$

$10.3 \%$

Educational attainment

Vocational college or above

Having someone to consult with

Knowing how to access consulting service

Spending almost all day for nursing care

Participation of nursing activities

\begin{tabular}{|lllll|}
\hline $18.7 \%$ & $(114 / 609)$ & $11.8 \%$ & $(4 / 34)$ & 0.308 \\
\hline $3.4 \%$ & $(21 / 609)$ & $14.7 \%$ & $(5 / 34)$ & 0.009 \\
\hline $0.5 \%$ & $(3 / 609)$ & $11.8 \%$ & $(4 / 34)$ & $<0.001$ \\
\hline
\end{tabular}

$23.2 \%$

$(141 / 609) \quad 38.2 \%$

$(13 / 34) \quad 0.045$ 


\begin{tabular}{|c|c|c|c|c|c|}
\hline Face washing & $17.7 \%$ & $(108 / 609)$ & $14.7 \%$ & $(5 / 34)$ & 0.652 \\
\hline Brushing teeth & $18.4 \%$ & $(112 / 609)$ & $11.8 \%$ & $(4 / 34)$ & 0.328 \\
\hline Bed bath & $14.1 \%$ & $(86 / 609)$ & $17.6 \%$ & $(6 / 34)$ & 0.613 \\
\hline Shampoo & $12.3 \%$ & $(75 / 609)$ & $20.6 \%$ & $(7 / 34)$ & 0.182 \\
\hline Changing clothes & $31.2 \%$ & $(190 / 609)$ & $38.2 \%$ & $(13 / 34)$ & 0.390 \\
\hline Bathing & $11.8 \%$ & $(72 / 609)$ & $20.6 \%$ & $(7 / 34)$ & 0.172 \\
\hline $\begin{array}{l}\text { Changing body positon/ daily } \\
\text { living }\end{array}$ & $11.5 \%$ & $(70 / 609)$ & $8.8 \%$ & $(3 / 34)$ & 0.787 \\
\hline Helping with toilet & $17.2 \%$ & $(105 / 609)$ & $20.6 \%$ & $(7 / 34)$ & 0.617 \\
\hline Fixing meals and cleaning up & $53.0 \%$ & $(323 / 609)$ & $41.2 \%$ & $(14 / 34)$ & 0.178 \\
\hline Assistance with eating & $18.4 \%$ & $(112 / 609)$ & $29.4 \%$ & $(10 / 34)$ & 0.111 \\
\hline Helping with medication & $55.2 \%$ & $(336 / 609)$ & $50.0 \%$ & $(17 / 34)$ & 0.555 \\
\hline Walking & $19.0 \%$ & $(116 / 609)$ & $17.6 \%$ & $(6 / 34)$ & 0.839 \\
\hline Cleaning up & $52.7 \%$ & $(321 / 609)$ & $35.3 \%$ & $(12 / 34)$ & 0.048 \\
\hline Laundry & $62.4 \%$ & $(380 / 609)$ & $50.0 \%$ & $(17 / 34)$ & 0.148 \\
\hline Shopping & $59.8 \%$ & $(364 / 609)$ & $35.3 \%$ & $(12 / 34)$ & 0.005 \\
\hline Conversation & $38.8 \%$ & $(236 / 609)$ & $35.3 \%$ & $(12 / 34)$ & 0.687 \\
\hline $\begin{array}{l}\text { Having subjective symptoms within } \\
\text { a few days }\end{array}$ & $43.0 \%$ & $(260 / 605)$ & $76.5 \%$ & $(26 / 34)$ & $<0.001$ \\
\hline with paid work & $45.0 \%$ & $(270 / 600)$ & $29.4 \%$ & $(10 / 34)$ & 0.075 \\
\hline visiting hospitals regularly & $57.9 \%$ & $(351 / 606)$ & $73.5 \%$ & $(25 / 34)$ & 0.072 \\
\hline \multicolumn{6}{|l|}{ Households } \\
\hline $\begin{array}{l}\text { Number of family members at } \\
\text { home }\end{array}$ & $3.5 \pm 1.4$ & $(n=609)$ & $3.5 \pm 1.5$ & $(n=34)$ & 0.939 \\
\hline $\begin{array}{l}\text { Other family members in need of } \\
\text { nursing care }\end{array}$ & $12.2 \%$ & $(74 / 609)$ & $20.6 \%$ & $(7 / 34)$ & 0.178 \\
\hline Having own house & $93.9 \%$ & $(572 / 609)$ & $79.4 \%$ & $(27 / 34)$ & 0.006 \\
\hline $\begin{array}{l}\text { Total household monthly } \\
\text { expenditure }\end{array}$ & $\begin{array}{l}31.9 \pm \\
63.3\end{array}$ & $(n=592)$ & $\begin{array}{l}24.0 \pm \\
13.2\end{array}$ & $(n=32)$ & 0.479 \\
\hline
\end{tabular}

Table 2. Factors associated with serious psychological distress of family caregivers for people with dementia. 
Odds ratio

(95\% Confidence interval)

Z

value

$p$ value

Nursing care recipients
Sex (being male)
2.83
$\left(\begin{array}{ll}1.20 & -6.69\end{array}\right)$
5.59
0.018

Family caregivers

Age

0.95

$\left(\begin{array}{ll}0.92 & -0.98\end{array}\right)$

8.72

0.003

Knowing how to access consulting service

$34.22 \quad(5.40 \quad-$

$14.05<0.001$

217.10)

Spending almost all day for nursing care

2.41

$(1.20$

$-5.51)$

4.36

0.037

Participation of nursing activities

Shopping

$\begin{array}{lllll}0.26 & (0.11 & -0.61) & 9.48 & 0.002\end{array}$

Having subjective symptoms within a few days

5.56

$\left(\begin{array}{ll}2.15 & -14.33\end{array}\right)$

12.57

$<0.001$

Households

Having own house

$0.19 \quad(0.06 \quad-0.58)$

8.59

0.003

\section{Figures}

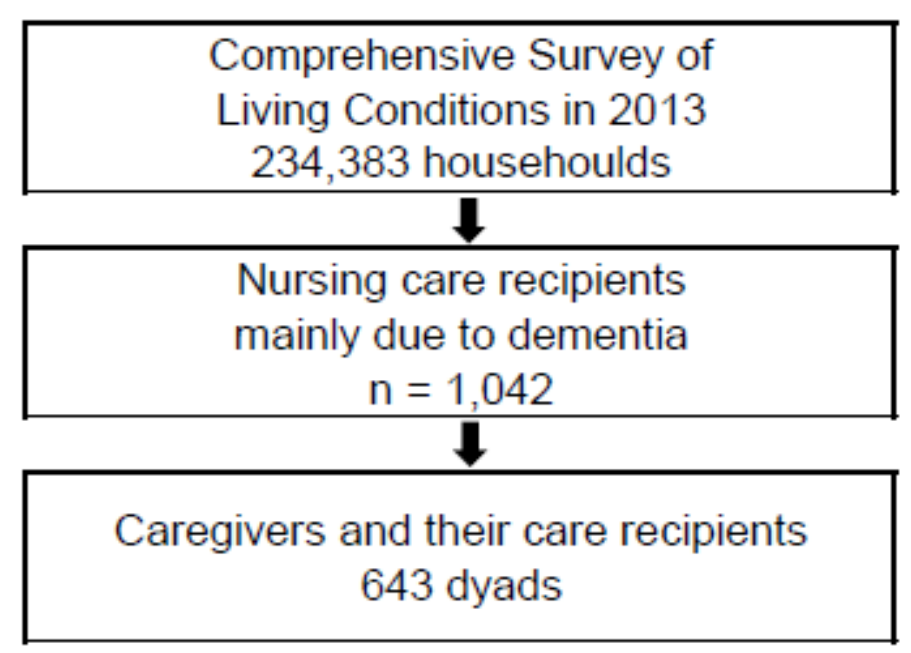

Figure 1

Flow chart of study sample 